\title{
AVALIAÇÃO DE PRECEPTORIA DE CIRURGIA GERAL EM HOSPITAL GERAL
}

Autores: AMARAL, Márcio José Cardoso

\section{Introdução}

A Residência Médica (RM) é o momento mais importante de aprendizado após a graduação, sendo caracterizada por treinamento em serviço. É o cenário no qual os processos teóricos e assistenciais precisam entrar em equilíbrio, quando fundamentos para o desenvolvimento de habilidades técnicas e o desenvolvimento comportamental, moldado pela ética e pelo espírito de cooperação, devem nortear a boa prática médica.

Recentemente, houve uma grande difusão do credenciamento de programas de residência em hospitais não universitários, municipais e estaduais. Gerando assim um grande contingente de cirurgiões chamados aleatoriamente de preceptores e desenvolvendo uma preceptoria intuitiva.

\begin{tabular}{|l|c|c|c|c|c|}
\hline \multicolumn{7}{|c|}{ Respostas } \\
\hline & Excelente (5,0) & Muito Bom (4,0) & Bom(3,0) & Regular (2,0) & Ruim (1,0) \\
\hline P1 & $100 \%$ & $0 \%$ & $0 \%$ & $0 \%$ & $0 \%$ \\
\hline P2 & $67 \%$ & $33 \%$ & $0 \%$ & $0 \%$ & $0 \%$ \\
\hline P3 & $67 \%$ & $33 \%$ & $0 \%$ & $0 \%$ & $0 \%$ \\
\hline P4 & $67 \%$ & $33 \%$ & $0 \%$ & $0 \%$ & $0 \%$ \\
\hline P5 & $100 \%$ & $0 \%$ & $0 \%$ & $0 \%$ & $0 \%$ \\
\hline P6 & $100 \%$ & $0 \%$ & $0 \%$ & $0 \%$ & $0 \%$ \\
\hline P7 & $100 \%$ & $0 \%$ & $0 \%$ & $0 \%$ & $0 \%$ \\
\hline P8 & $100 \%$ & $0 \%$ & $0 \%$ & $0 \%$ & $0 \%$ \\
\hline P9 & $100 \%$ & $0 \%$ & $0 \%$ & $0 \%$ & $0 \%$ \\
\hline P10 & $67 \%$ & $0 \%$ & $33 \%$ & $0 \%$ & $0 \%$ \\
\hline P11 & $100 \%$ & $0 \%$ & $0 \%$ & $0 \%$ & $0 \%$ \\
\hline P12 & $100 \%$ & $0 \%$ & $0 \%$ & $0 \%$ & $0 \%$ \\
\hline P13 & $50 \%$ & $0 \%$ & $50 \%$ & $0 \%$ & $0 \%$ \\
\hline Geral & $84 \%$ & $10 \%$ & $6 \%$ & $0 \%$ & $0 \%$ \\
\hline
\end{tabular}

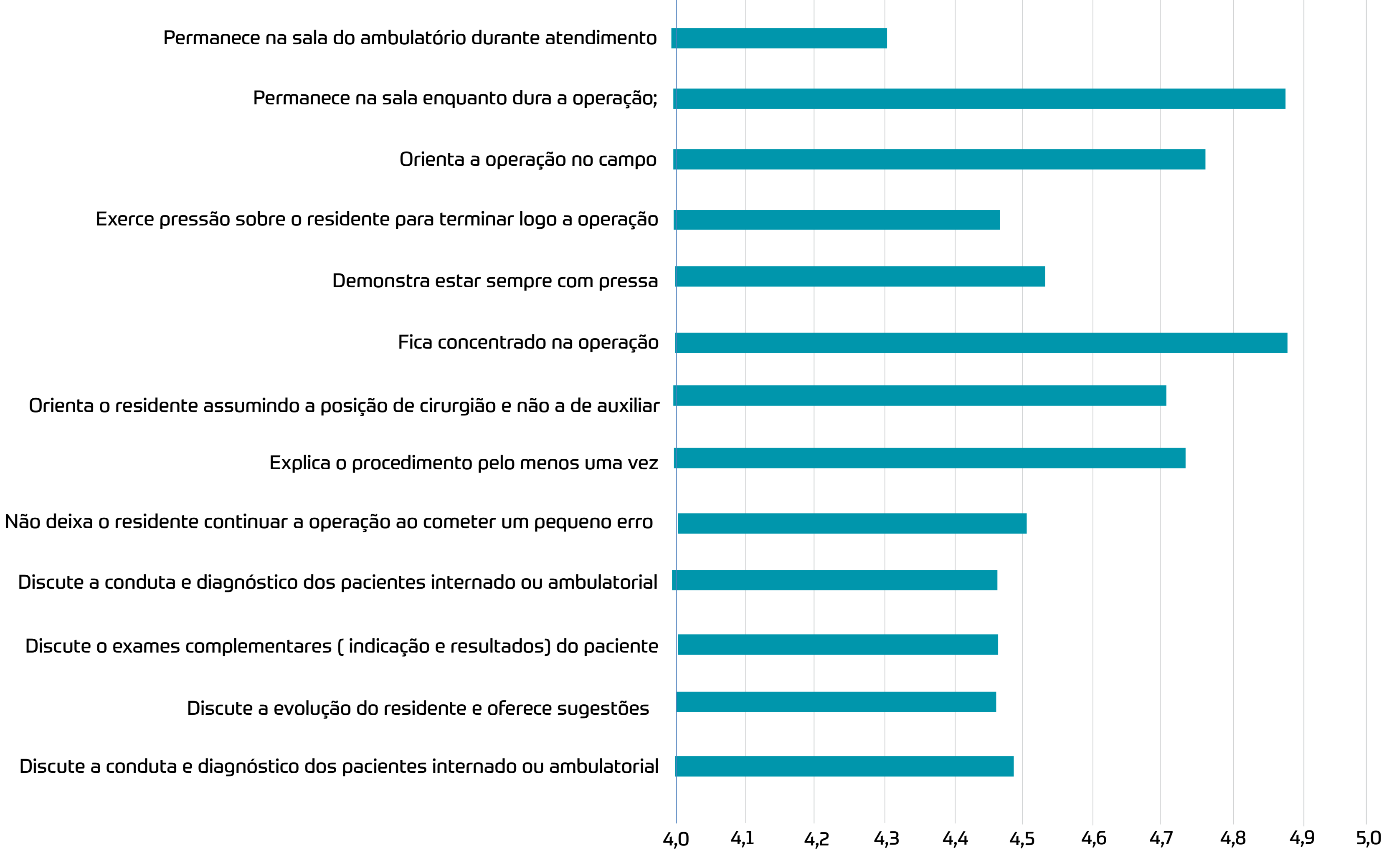

\section{Objetivo:}

Determinar se o cirurgião que exerce sua carga horária apenas em setores de emergência cirúrgica sem vínculo formal com a residência médica possui um desempenho profissional adequado em relação a formação do médico residente de cirurgia geral.

\section{Métodos}

O Serviço de Cirurgia Geral do Hospital Regional de Cotia (HRC) conta com o programa de residência médica em Cirurgia Geral credenciados em 2014 pela CNRM/MEC disponibilizando três vagas anuais para concurso público de admissão. Foram avaliados 13 cirurgiões no período de janeiro de 2017 à março de 2018. Foi aplicado um questionário a todos os residentes trimestralmente via núcleo de ensino e pesquisa do HRC de modo a qualificar o item pesquisado sobre as atitudes dos preceptores. O critério de inclusão dos preceptores foi: supervisão direta por mais de seis meses. O núcleo de ensino e pesquisa foi responsável pela codificação dos preceptores e esse código só foi conhecido pelos próprios residentes garantindo o anonimato das respostas.

Os seguintes itens foram avaliados: 1] Não deixa o residente continuar a operação ao cometer um pequeno erro; 2] Explica o

procedimento pelo menos uma vez; 3) Orienta o residente assumindo a posição de cirurgião e não a de auxiliar; 4] Fica concentrado na operação; 5) Demonstra estar sempre com pressa; 6] Exerce pressão sobre o residente para terminar logo a operação; 7) Orienta a operação no campo; 8] Permanece na sala enquanto dura a operação; 9] Supervisiona de maneira agressiva; 10] Discute a evolução do residente e oferece sugestões.

As respostas foram distribuídas da seguinte maneira: a] Excelente [5], b] Muito bom [4], c] Bom [3], d) Ruim [2], e] Péssimo (1], f) NA [0].

Resultados: Foram avaliados 13 cirurgiões por 12 médicos residentes e obtidas 780 questionários válidas e demonstradas em forma de tabela (tabela le gráfico 1).

\section{Discussão}

Sempre houve um "entendimento" de que os cirurgiões são capazes de exercer a função de preceptoria, mas nunca se verificou se os responsáveis pelo treinamento podem, de fato e de direito, se apossar do título "preceptor". O estudo sugere que os profissionais não vinculados a residência médica de maneira formal conseguem desenvolver a atividade de preceptoria de forma satisfatória. 